\title{
Workplace-specific challenges as a contribution to the diagnosis of occupational asthma
}

\author{
J-P. Rioux, J-L. Malo, J. L’Archevêque, K. Rabhi and M. Labrecque
}

ABSTRACT: The diagnosis of occupational asthma can be made by exposing workers to the relevant agent either in a hospital laboratory through specific inhalation challenges (SICs) or in the workplace. As suggested by several authors, workers with negative laboratory SIC can be monitored at the workplace under supervision. The present study aims to assess the frequency of, and identify factors associated with, a positive workplace reaction in workers with negative SIC in the laboratory.

The results of workplace challenges were examined in 99 workers who underwent negative SIC between 1994 and 2004. A positive reaction either in the SIC or in the workplace was defined as a sustained fall in forced expiratory volume in one second of $\geqslant 20 \%$.

In total, 22 (22.2\%) workers showed positive responses at the workplace. These subjects more often had increased baseline methacholine responsiveness (90.5 versus $67.6 \%$ ). They also underwent more days of SIC testing (4.9 versus 3.3 days) and were exposed more often to two or more agents (56 versus 28.4\%) and for a longer period of time (363.3 versus $220.4 \mathrm{~min}$ ) in the laboratory.

The present study illustrates the usefulness of workplace monitoring of airway function in the investigation of occupational asthma and identifies factors that are more often associated with a positive reaction.

KEYWORDS: Asthma, occupational asthma, specific challenges, workplace

ccupational asthma is a disease characterised by variable airflow limitation and/or airway hyperresponsiveness and/or inflammation due to causes and conditions attributable to the workplace [1]. It has been estimated that up to $10 \%$ of adult onset asthma is related to exposure in the workplace [2]. The diagnosis of occupational asthma should be confirmed by objective tests [3] since it has major medico-legal and socioeconomic consequences [4]. Many diagnostic tools can be used for the evaluation of occupational asthma [3]: questionnaires; immunological tests; peak flow monitoring at and away from work; assessment of methacholine bronchial hyperresponsiveness; and assessment of airway inflammation by induced sputum or exhaled nitric oxide [5]. These tests are usually carried out in a stepwise fashion using an algorithm. However, several pitfalls have been addressed for each of these methods regarding their sensitivity and specificity, in addition to their inability to identify the agent responsible for occupational asthma.
Specific inhalation challenges (SIC) are considered the gold standard for the diagnosis of occupational asthma [6, 7]. The tests, originally proposed by PEPYS and HuTCHCROFT [8], consist of exposing a worker in a hospital laboratory to a possible offending agent and monitoring airway calibre. Monitoring airway hyperresponsiveness and inflammation can improve the diagnostic yield during these tests [5]. Improvement in this methodology by better direct control of exposure using generators has been proposed $[6,7]$ and has been shown to improve the safety of testing [9].

Although this exposure can identify the causal agent and confirm the diagnosis of occupational asthma, additional monitoring at work under the supervision of a technician is also relevant, as it proposes a "real life" situation in which the worker is exposed not only to one single agent at a time in the laboratory, but to all potential causal agents at work. This approach, however, makes the assumption that the "real life" scenario at the workplace is representative of the usual exposure.
AFFILIATIONS

Dept of Chest Medicine, Hôpital du Sacré-Coeur de Montréal, Montreal, QC, Canada.

\section{CORRESPONDENCE}

M. Labrecque

Dept of Chest Medicine

Hôpital du Sacré-Coeur de Montréal

5400 West Gouin Blvd

Montreal

QC

Canada H4J 1 C5

Fax: 15143383123

E-mail: manon.labrecque@

UMontreal.ca

Received:

August 032007

Accepted after revision:

May 072008

STATEMENT OF INTEREST

None declared.

European Respiratory Journal

Print ISSN 0903-1936

Online ISSN 1399-3003 
Considering the potential superiority of workplace monitoring in comparison with SIC in the laboratory, the current authors have adapted a procedure in recent years in which the worker is first exposed to potential sensitisers in the hospital laboratory and, if the tests are negative, sent back to work, and monitored by a technician on the first 2 days after returning to work. This procedure is particularly advocated if there are several potential sensitising agents, or possible ones not yet reported, as causes of occupational asthma at the workplace. The validity of this approach has not yet been evaluated in specific regard to the frequency of positive reactions at work in the case of negative testing at the hospital. In fact, the "prevalence of false negative tests (in the laboratory) has not been assessed prospectively by returning the worker to the workplace and examining changes in functional status," as previously suggested [10].

In the present study, the retrospective prevalence of positive SIC in the workplace for workers with negative challenges at the hospital was examined, using the database of the present authors' institution. The present study also planned to identify factors that may be predictors of a positive SIC at the workplace and negative challenges at the hospital.

\section{MATERIALS AND METHODS}

\section{Design and source of data}

The present retrospective study used the database of all subjects investigated for occupational asthma from January 1994 to December 2004 by the Dept of Chest Medicine, Hôpital du Sacré-Coeur de Montréal (Montreal, QC, Canada). Since 1994, workers with negative tests at the hospital laboratory have undergone challenges at the workplace under the supervision of a technician if more than one potential sensitising agents was present at the workplace, or if the worker's history was highly suggestive of occupational asthma using clinical criteria (major improvement or disappearance of asthmatic symptoms while away from work and reappearance on return to work) [5], even in the absence of a workplace agent known to cause occupational asthma. The characteristics of workers with initial negative SIC at the hospital laboratory who underwent subsequent challenges at the workplace (with or without positive results) were examined and compared.

\section{SIC tests}

The protocol used for the evaluation of occupational asthma in the Hôpital du Sacré-Coeur de Montréal has previously been described [6, 7]. In brief, the first day of evaluation was the control day, which consisted of obtaining baseline spirometry and monitoring forced expiratory volume in one second (FEV1) every $10 \mathrm{~min}$ for $1 \mathrm{~h}$, every $30 \mathrm{~min}$ for $2 \mathrm{~h}$ and hourly for $7-8 \mathrm{~h}$. At the end of the day, bronchial responsiveness to methacholine was assessed. Induced sputum is currently obtained but since this procedure has been recently introduced on a routine basis, these results were not examined in the current study. If fluctuations in FEV1 on day one did not exceed $10 \%$, the worker was called in on the second day, which is the control day of exposure. If not, medication could be modified to achieve a more stable asthmatic situation. On the second day, the worker was exposed for 30-120 $\mathrm{min}$ to a control agent (viz. xylol in the case of isocyanates, a control wood dust, lactose if flour is the suspected agent, etc.). If FEV1 remained within $10 \%$ of the baseline value for the first day and there were no significant fluctuations in FEV1, the worker underwent exposure to the suspected occupational agent.

The worker was subsequently exposed to the suspected agent in a progressive manner: one breath, $10 \mathrm{~s}, 20 \mathrm{~s}, 30 \mathrm{~s}, 2 \mathrm{~min}$, $5 \mathrm{~min}, 30 \mathrm{~min}$ and so on, up to $2 \mathrm{~h}$. For high molecular-weight (proteinaceous) agents, exposure was carried out on a single day. For low molecular-weight (chemical) agents that may induce isolated late or atypical asthmatic reactions, the exposure was split into 3 or 4 days. After each exposure period, FEV1 was monitored regularly; every $10 \mathrm{~min}$ for $1 \mathrm{~h}$, every $30 \mathrm{~min}$ for $2 \mathrm{~h}$ and hourly for $7-8 \mathrm{~h}$. Depending on the agent, a challenge using specific equipment that controls exposure is preferred to the realistic method. At the end of the SIC at the hospital, bronchial responsiveness was again monitored.

During the period of SIC in the laboratory and at the workplace, the daily dose of inhaled steroids was kept constant, the medication being taken once a day (and not separated into two daily doses) in the evening. Long-acting $\beta_{2^{-}}$ adrenergic agents were stopped 3 days before testing and a short-acting $\beta_{2}$-adrenergic agent was used if needed.

If the objective evaluation at the hospital laboratory did not allow a confirmation of occupational asthma, workplace exposure and monitoring were performed at the workplace under the supervision of a technician. As for SIC in the hospital laboratory, the subject first underwent a control nonexposure day at the hospital, at which time functional monitoring was carried out, before returning to the workplace. During this maximum 2 days of 7-8 h evaluation (if no significant change in FEV1 occurs), the worker was asked to do their usual work and FEV1 is monitored regularly. If a significant fall in FEV1 occured before the end of this exposure, the worker was removed from the workplace. At the end of this evaluation, bronchial responsiveness to methacholine was assessed. If no significant change in FEV1 occurred, the worker remained at work and monitored (every $2 \mathrm{~h}$ during daytime) their peak expiratory flow (PEF). After 2 weeks, a visit was made to the hospital laboratory for assessment of spirometry and responsiveness to methacholine.

\section{Analysis}

Spirometry was assessed according to the American Thoracic Society criteria [11]. Significant bronchial hyperresponsiveness was set at a concentration of methacholine causing a $20 \%$ fall of FEV1 (PC20) using a standardised procedure with the Wright's nebuliser at tidal volume breathing (output of nebuliser $0.14 \mathrm{~mL} \cdot \mathrm{min}^{-1}$ ) [12]. Significant changes in PC20 were defined in two different groups, as $\geqslant 3$.2-fold [13] and $\geqslant 2$-fold changes in concentration from one test to the text. For the purposes of the present study, a positive test on either the SIC or the workplace test was defined as a sustained decline (at least two values) in FEV1 that reached $20 \%$. The prevalence of positive SIC at the workplace when challenges were negative in the hospital laboratory was assessed.

In the Hôpital du Sacré-Coeur de Montréal, a database on all workers investigated for possible occupational asthma is available and information on each worker is entered at the time the investigation, including SIC, is completed. The following information was collected from the database for 
each subject who met the inclusion criteria: age; sex; smoking status; presence or absence of atopy (defined by at least one positive wheal $(\geqslant 3 \mathrm{~mm}$ ) skin reaction by the prick method to a battery of 15 ubiquitous inhalants in the presence of a positive control (histamine phosphate $1 \mathrm{mg} \cdot \mathrm{mL}^{-1}$ ) and a negative reaction to a saline solution); medication taken by the worker at the time of the SIC; duration of symptoms; duration of exposure to the potential causal agent at the workplace before evaluation; the nature of the potential causal agent; duration of exposure to the causal agent in the hospital and workplace challenges; the number of SIC days it took for the total evaluation of the patient; and the final diagnosis. Functional status was assessed by FEV1, FEV1/forced vital capacity (FVC) and PC20 at the beginning and end of the SIC. These parameters were compared in subjects with and without positive reactions in the workplace.

An unpaired t-test was used to compare the means of continuous variables between the two groups. Pearson's Chisquared test was used for categorical variables.

\section{RESULTS}

In total, 99 subjects with negative SIC at the hospital underwent challenge monitoring at the workplace between January 1994 and December 2004. In this period, 622 subjects underwent SIC in the laboratory only and were considered to be nonparticipants. Table 1 shows the baseline characteristics of the participants and the nonparticipants. These were similar, except for a higher prevalence of atopic subjects and workers treated with inhaled steroids in the group of participants.

SIC at the workplace was suggested in the 99 subjects with negative SIC at the hospital because there was more than one known sensitising agent at the workplace and/or the history was highly suggestive of occupational asthma using clinical criteria (major improvement or disappearance of asthmatic symptoms while away from work and reappearance on return to work) [5]. The maximum fall in FEV1 at the workplace was $26.5 \pm 10.1 \%$ in subjects with positive ( $\geqslant 20 \%$ changes in FEV1) workplace challenges, in comparison with $6.0 \pm 3.8 \%$ for subjects with negative reactions. Only one subject had changes in FEV1 between 15 and 19\% in SIC in the hospital laboratory (test considered as negative). Of the 77 negative challenges in the workplace, seven were later considered to have occupational asthma. A second series of tests at the hospital laboratory, carried out after the negative tests performed in the workplace, showed a positive reaction in these cases to an agent that was different from the agent tested in the hospital laboratory. These seven subjects were not significantly different from the 22 subjects with positive workplace challenges in terms of sex, age, atopic and smoking status, duration of work exposure, duration of work exposure with symptoms, nature of occupational agent, baseline spirometry and PC20. The remaining subjects had nonsignificant changes in PEF during the 2 weeks of monitoring at work and no change in spirometry and responsiveness to methacholine when assessed 2 weeks after their return to work. They were considered to have nonoccupational asthma $(n=29$; respiratory symptoms and $\left.\mathrm{PC}_{20} \leqslant 16 \mathrm{mg} \cdot \mathrm{mL}^{-1}\right)$, occupational rhinitis $(n=5$; onset of rhinitis symptoms on laboratory challenges but no occupational asthma), hyperventilation $(n=14$; hyperventilation symptoms on laboratory challenges with arterial carbon dioxide tension $<30 \mathrm{mmHg}(4.0 \mathrm{kPa})$ ), irritant-induced asthma $(n=2$; history of exposure to high concentrations of an agent at work with $\mathrm{PC} 20 \leqslant 16 \mathrm{mg} \cdot \mathrm{mL}^{-1}$ ) or no specific nasal or chestrelated occupational disease was diagnosed $(n=20$; the remaining subjects).

The baseline characteristics of the 99 subjects according to the results of workplace challenges are shown in table 2 . The present sample was principally made up of middle-aged atopic males. The vast majority of subjects were taking asthma medication, mostly inhaled corticosteroids. The mean duration of exposure to the potential offending agent before SIC tests was $8.5 \mathrm{yrs}$ and subjects had been symptomatic of workrelated asthma for a mean duration of 3 yrs before undergoing evaluation for occupational asthma. The vast majority of subjects were exposed to low molecular-weight agents. A total of $24(24 \%)$ subjects had an FEV1 $<80 \%$ predicted and an FEV1/FVC ratio $<70 \%$ was found in $14(14 \%)$ subjects. Bronchial hyperresponsiveness ( $\mathrm{PC} 20 \leqslant 16 \mathrm{mg} \cdot \mathrm{mL}^{-1}$ ) was present in $68(72 \%)$ subjects. Subjects with positive workplace challenges more often showed bronchial hyperresponsiveness at baseline. Workers with positive workplace challenges had been away from work for a shorter interval at the time of investigation: $3.9 \pm 5.7$ versus $12.2 \pm 24.5$ weeks $(p<0.01$; data not shown in table 2). However, a similar proportion of workers who had been away from work for $<2$ weeks had

\begin{tabular}{|c|c|c|}
\hline \multirow[t]{3}{*}{ TABLE 1} & $\begin{array}{l}\text { racteristics of pe } \\
\text { nts }\end{array}$ & rticipants and \\
\hline & \multicolumn{2}{|c|}{ Workplace challenges } \\
\hline & Carried out & Not carried out \\
\hline Subjects $\mathbf{n}$ & 99 & 622 \\
\hline Sex males/females & $64 / 35(65 / 35)$ & $418 / 204(67 / 33)$ \\
\hline Age yrs & $39.8 \pm 11.3$ & $40.3 \pm 11.2$ \\
\hline $\begin{array}{l}\text { Smoking habit status } \\
\text { smokers/ex-smokers/ } \\
\text { nonsmokers }\end{array}$ & $32 / 25 / 42(32 / 25 / 42)$ & $153 / 219 / 232(25 / 36 / 39)$ \\
\hline Atopy $^{\#}$ present/absent & $70 / 26(73 / 27)$ & $319 / 288(51 / 49)$ \\
\hline $\begin{array}{l}\text { Treatment with inhaled } \\
\text { steroids }\end{array}$ & $72(72)$ & $285(46)$ \\
\hline Duration of exposure yrs & $8.5 \pm 11.0$ & $11.0 \pm 10.5$ \\
\hline $\begin{array}{l}\text { Duration of exposure with } \\
\text { symptoms yrs }\end{array}$ & $3.0 \pm 4.6$ & $3.2 \pm 4.3$ \\
\hline $\begin{array}{l}\text { Occupational agent tested } \\
\text { in the laboratory low/high } \\
\text { molecular-weight agents }\end{array}$ & $79 / 20(80 / 20)$ & 414/193 (68/32) \\
\hline $\begin{array}{l}\text { Time since last workplace } \\
\text { exposure weeks }\end{array}$ & $10.3 \pm 22.0$ & $17.8 \pm 65.9$ \\
\hline FEV $1 \%$ pred & $91.1 \pm 17.8$ & $92.9 \pm 19.9$ \\
\hline FEV $_{1} /$ FVC $\%$ pred & $92.3 \pm 12.0$ & $92.2 \pm 11.5$ \\
\hline $\mathrm{PC}_{20} \leqslant 16 \mathrm{mg} \cdot \mathrm{mL}^{-1}$ & $69(70)$ & $373(61)$ \\
\hline \multicolumn{3}{|c|}{$\begin{array}{l}\text { Data are presented as } n(\%) \text { or mean } \pm \mathrm{SD} \text {, unless otherwise stated. } \mathrm{FEV} 1 \text { : forced } \\
\text { expiratory volume in one second; } \% \text { pred: } \% \text { predicted; FVC: forced vital } \\
\text { capacity; PC20: provocative dose causing a } 20 \% \text { fall in FEV1. }{ }^{\#} \text { : atopy was } \\
\text { defined as at least one immediate reaction to a battery of } 15 \text { ubiquitous } \\
\text { allergens by the prick method. }\end{array}$} \\
\hline
\end{tabular}




\begin{tabular}{|c|c|c|c|c|c|c|c|c|c|}
\hline \multirow[t]{3}{*}{ TABLE 2} & cs of suk & s with $p$ & tive or & yative wc & ce challe & , with & nction ac & rding to & ation of \\
\hline & \multicolumn{3}{|c|}{ All subjects } & \multicolumn{3}{|c|}{$\begin{array}{c}\text { Cessation of exposure at work } \\
<2 \text { weeks }\end{array}$} & \multicolumn{3}{|c|}{$\begin{array}{c}\text { Cessation of exposure at work } \\
\qquad 2 \text { weeks }\end{array}$} \\
\hline & Positive & Negative & $\mathrm{p}$-value & Positive & Negative & p-value & Positive & Negative & $\mathrm{p}$-value \\
\hline Age yrs & $36.8 \pm 9.7$ & $40.7 \pm 11.6$ & 0.16 & $37.3 \pm 10.5$ & $41.1 \pm 10.9$ & 0.98 & $39.9 \pm 12.8$ & $36.9 \pm 9.7$ & 0.12 \\
\hline $\begin{array}{l}\text { Smoking habit status } \\
\text { smokers/ex-smoker/ } \\
\text { nonsmokers }\end{array}$ & $7 / 4 / 11$ & $25 / 21 / 31$ & 0.62 & $3 / 1 / 7$ & $12 / 9 / 15$ & 0.37 & $4 / 3 / 2$ & $11 / 9 / 14$ & 0.58 \\
\hline Atopy present/absent $n$ & $16 / 5$ & $54 / 21$ & 0.79 & $9 / 2$ & $25 / 10$ & 0.40 & $5 / 3$ & $24 / 9$ & 0.43 \\
\hline \multicolumn{10}{|l|}{ Occupational agent $^{+} n$} \\
\hline Low molecular-weight & 17 & 62 & 0.90 & 8 & 29 & 0.64 & 7 & 27 & 0.62 \\
\hline High molecular-weight & 5 & 15 & 0.90 & 2 & 7 & 0.64 & 2 & 7 & 0.62 \\
\hline FEV $1 \%$ pred & $89.9 \pm 16.8$ & $91.4 \pm 18.2$ & 0.73 & $89.6 \pm 20.0$ & $87.3 \pm 15.4$ & 0.41 & $91.4 \pm 15.3$ & $91.6 \pm 19.8$ & 0.15 \\
\hline FEV $_{1 / \text { FVC } \% \text { pred }}$ & $91.0 \pm 10.8$ & $92.7 \pm 12.3$ & 0.84 & $90.5 \pm 14.4$ & $89.9 \pm 11.1$ & 0.39 & $95.1 \pm 8.9$ & $91.7 \pm 12.0$ & 0.18 \\
\hline $\mathrm{PC}_{20} \leqslant 16 \mathrm{mg} \cdot \mathrm{mL}^{-1}$ & $19(91)$ & $50(68)$ & 0.05 & $10(91)$ & $31(86)$ & 0.66 & 7 (78) & $16(47)$ & 0.06 \\
\hline
\end{tabular}

Data are presented as $\mathrm{n}(\%)$ or mean \pm SD, unless otherwise stated. FEV1: forced expiratory volume in one second; \% pred: \% predicted; FVC: forced vital capacity; PC20:


a battery of 15 ubiquitous allergens by the prick method; ${ }^{+}$: tested in the laboratory in the first instance.

positive workplace challenges (11 $(23 \%)$ out of 47$)$ in comparison to the proportion of those who had been away from work for $\leqslant 2$ weeks (nine $(21 \%)$ out of 43 ). Moreover, the baseline characteristics of subjects with negative or positive workplace challenges according to cessation of exposure at work ( $<2$ weeks compared with $\geqslant 2$ weeks) were not significantly different (table 2).

Table 3 lists features related to the laboratory and workplace challenges according to the results of workplace challenges. The duration of laboratory challenges in terms of number of days spent in the hospital laboratory and duration of exposure in laboratory challenges were longer in those with positive challenges. More than half of positive reactors were exposed to two or more agents in the laboratory, which was twice as many as for negative reactors. When a subject was exposed to two or more agents they were always agents of the same category, i.e. low molecular-weight agents. This includes the four subjects exposed to both isocyanates and acrylates. The duration of exposure in the workplace (total number of minutes spent) tended to be longer in those with negative challenges. Although all subjects with negative challenges in the laboratory had falls in FEV $1<20 \%$, the maximum changes in FEV1 were more significant in workers with positive challenges in the workplace. Changes in PC20 after the workplace challenges, either $\geqslant 3.2$-fold or $\geqslant 2$-fold, were more often found in those with positive workplace challenges. Subjects whose PC20 changed by $\geqslant 2$-fold were not significantly different from those who did not in terms of sex, age, atopy, treatment with inhaled steroids, duration of exposure, nature of occupational agent, baseline FEV1, FEV1/FVC and PC20. However, there was a significant difference in the duration of exposure with symptoms $(4.5 \pm 9.1$ versus $2.4 \pm 2.6$ yrs; $p=0.005)$.

\section{DISCUSSION}

The present study shows that challenges in the workplace are a useful complement for the investigation of workers with possible occupational asthma when SIC is negative in a hospital laboratory. Challenges in the workplace indeed confirmed occupational asthma in 22 (22\%) of 99 subjects with negative investigation at the hospital. This approach is particularly indicated in workers: 1) exposed to two or more agents known to cause occupational asthma; 2) with increased baseline nonspecific bronchial hyperresponsiveness; 3) who undergo longer testing days in the laboratory; and 4) who have left their workplace for a short interval.

The present results are also particularly relevant for workers exposed to low molecular-weight (chemical) agents, which represented $>80 \%$ of the present authors' challenge cases. High molecular-weight agents generally cause immediate or dual asthmatic reactions and are generally simpler to administer, and dose-response curves are easier to generate. With low molecular-weight agents, the reaction is generally late or atypical and is more difficult to predict. For these reasons, workers with negative SIC in the laboratory frequently need to be studied at their workplace. In the vast majority of cases, there is no problem returning a worker to his/her workplace 


\begin{tabular}{|c|c|c|c|c|}
\hline \multirow{3}{*}{\multicolumn{2}{|c|}{ TABLE 3}} & $\begin{array}{l}\text { of challenge } \\
\text { nonreactors }\end{array}$ & s in workpla & \\
\hline & & \multicolumn{3}{|c|}{ Workplace challenge } \\
\hline & & Positive & Negative & $\mathrm{p}$-value \\
\hline \multicolumn{2}{|l|}{ Subjects $n$} & 22 & 77 & \\
\hline \multicolumn{2}{|c|}{$\begin{array}{l}\text { Duration of laboratory } \\
\text { challenges days }\end{array}$} & $4.9 \pm 3.6$ & $3.3 \pm 1.6$ & 0.004 \\
\hline \multicolumn{2}{|c|}{$\begin{array}{l}\text { Duration of exposure in } \\
\text { laboratory challenges min }\end{array}$} & $363.3 \pm 294.3$ & $220.4 \pm 137.0$ & 0.002 \\
\hline \multicolumn{2}{|c|}{$\geqslant 2$ agents tested } & $14(56)$ & $21(28)$ & 0.002 \\
\hline \multicolumn{2}{|c|}{$\begin{array}{l}\text { Duration of exposure } \\
\text { at the workplace min }\end{array}$} & $493.2 \pm 446.7$ & $635.4 \pm 309.2$ & 0.092 \\
\hline \multicolumn{2}{|c|}{$\begin{array}{l}\text { Maximum fall in FEV } 1 \\
\text { in laboratory challenges \% } \\
\text { of baseline }\end{array}$} & $13.8 \pm 9.6$ & $7.9 \pm 6.7$ & $<0.001$ \\
\hline \multicolumn{2}{|c|}{$\begin{array}{c}\text { Change in } \mathrm{PC}_{20} \geqslant 3.2 \text {-fold } \\
\text { at the workplace }\end{array}$} & $9 / 19(47)$ & 9/67 (13) & 0.003 \\
\hline \multicolumn{2}{|c|}{$\begin{array}{c}\text { Change in } \mathrm{PC}_{20} \geqslant 3.2 \text {-fold } \\
\text { in laboratory challenges }\end{array}$} & $5 / 19(26)$ & 9/73 (12) & 0.16 \\
\hline \multicolumn{2}{|c|}{$\begin{array}{l}\text { Change in } \mathrm{PC}_{20} \geqslant 2 \text {-fold } \\
\text { at the workplace }\end{array}$} & 10/19 (53) & $16 / 67(24)$ & 0.01 \\
\hline \multicolumn{2}{|c|}{$\begin{array}{l}\text { Change in } \mathrm{PC}_{20} \geqslant 2 \text {-fold } \\
\text { in laboratory challenges }\end{array}$} & $7 / 19(37)$ & 18/73 (25) & 0.42 \\
\hline
\end{tabular}

Data are presented as $\mathrm{n}(\%)$ or mean $\pm \mathrm{SD}$, unless otherwise stated. FEV1: forced expiratory volume in one second; PC20: provocative dose causing a $20 \%$ fall in FEV1.

with a technician. Also, since this expertise is carried out in a context of a medico-legal expertise aimed at confirming or dismissing occupational asthma, most employers generally agree to these tests being carried out.

Factors that are more often associated with positive challenges at the workplace were also documented. Indications for workplace challenges can therefore be reasonably deduced from the present findings. First, when methacholine bronchial responsiveness is increased at baseline, suggesting the presence of either occupational or nonoccupational asthma, workplace challenges are more likely to be positive. Secondly, workplace challenges were more often positive in instances where two or more agents were tested in the hospital laboratory, requiring longer periods of testing and longer exposure to potential causal agents. In this instance, the physician responsible for testing was more likely to send the worker back to work with functional supervision. Economic considerations are unlikely to have affected the physician's decision. SIC in the laboratory or at the workplace are costly in terms of personnel required for testing but their cost is comparable in both. However, it is possible that a longer procedure in the laboratory induced a re-sensitising process in subjects who had stopped being exposed for a certain period of time. In this regard, workers with positive workplace challenges had been away from work for a shorter interval at the time of the investigation, although a similar proportion of workers with negative and positive workplace challenges were still at work when the investigation was started. There is some desensitisation after stopping exposure [14, 15], although this phenomenon is rarely complete [14] and is probably more likely in the case of isocyanates [15].

Workers who underwent SIC at the workplace were selected on the basis that they were either exposed to more than one potential sensitising agent at work and/or had a history highly suggestive of occupational asthma. The presence of $22 \%$ positive workplace challenges from 99 cases further emphasises the fact that a clinical questionnaire administered to workers with possible occupational asthma is sensitive but not specific [16], and probably more so if the investigation is carried out for medico-legal purposes.

The present findings show that positive reactors in the workplace were increasingly likely to have experienced more significant changes in FEV1 after the SIC, though still $<20 \%$. Furthermore, it is likely that the attending physician suspected that an asthmatic reaction was building up, which would become significant on returning to the workplace. Therefore, in subjects with minimal changes in FEV1 on SIC, it appears that returning to work would be fruitful in eliciting an asthmatic reaction.

In the current study, only one criterion was set for defining a positive reaction, which was a sustained fall in FEV1 of $\geqslant 20 \%$, either in the laboratory or the workplace. The current authors acknowledge that there are instances in which clinical judgment, changes in methacholine bronchial responsiveness and inflammatory status can change a diagnosis based only on changes in FEV1. As shown in table 3, 14 subjects, either workplace reactors or nonreactors, had significantly changed PC20 after laboratory SICs and in 18 subjects PC20 changed after exposure in the workplace. These findings could influence a diagnosis, because isolated changes in PC20 without changes in FEV1 have been found after exposing subjects to occupational agents [17], including isocyanates [18], and can be interpreted as an early marker of asthma [19]. Similarly, the present study did not take into account changes in airway inflammation that can be assessed either by exhaled nitric oxide or induced sputum. Examination of the level of eosinophils is a useful adjunct to diagnosis [20]. Sputum neutrophils may also rise after exposure to isocyanates [21]. Since the retrospective assessment was carried out for workers investigated from 1994 to 2004, data on sputum cells were generally not available.

Interestingly, seven workers had negative SIC followed by negative challenges in the workplace and subsequent positive SIC, evoking the possibility of false-negative reactions in the workplace. In the same way that SICs in the laboratory can be falsely negative if the wrong agent is used for challenges, workplace challenges can be negative if working conditions are not the same as those experienced by the worker at the time they were symptomatic. The technicians in the current study indicated whether in the opinion of the workers conditions were similar to usual. In seven cases, the technician's visit to the workplace had made it possible to identify other potential causal agents that could have been tested later in the laboratory SIC. In these seven subjects, it is also possible that re-exposure at the workplace re-initiated "sensitisation" to the causal agent, which resulted in a subsequent positive SIC in the hospital laboratory. In this regard, it would be interesting to compare results of SICs in the hospital laboratory with 
workplace challenge results not only in subjects with negative SIC (as completed in the present study), but also in workers with positive SIC in the hospital laboratory, in order to identify the proportion of workers who would have negative and positive SIC on return to their workplace.

Possible misclassifications could have occurred in the current subjects with positive and negative workplace challenges. In subjects with negative SIC in the laboratory and positive workplace challenges, the possibility cannot be excluded that the observed changes in FEV1 had been related to an "aggravation" of asthma due to exposure to a potential irritant agent and not necessarily because the worker was "sensitised" to an agent present at the workplace. Environmental monitoring of all potential sensitisers and irritant material was indeed not carried out at the time of workplace challenges. However, nearly $50 \%$ of subjects with negative laboratory SIC and positive workplace challenge experienced a change in their PC20 (table 3), which suggests that changes in FEV1 had occurred through a sensitising process, although it cannot be entirely ruled out that exposure to irritants in the workplace had caused changes in PC20.

In subjects with negative workplace challenges, 2 days of monitoring at work could not be sufficient for detecting functional changes. However, a longer monitoring period with the presence of a technician would be unpractical and costly. In the present authors' centre, workers are kept at work after these 2 days and they monitor their PEF. After a period of 2 weeks, they return to the hospital laboratory for assessment of spirometry and responsiveness to methacholine. This procedure could reasonably exclude the possibility of falsenegative workplace challenges.

In conclusion, the investigation of occupational asthma is a dynamic process that, in many instances, is comparable to an investigation by Sherlock Holmes. At-work and off-work unsupervised monitoring of peak expiratory flows is one option [22]. With this, there is no direct supervision of the monitoring, which a specific inhalation challenge at the workplace allows for, and recording can be improperly carried out or data falsified [23]. The current authors conclude that specific inhalation challenges in the workplace are a useful adjunct to laboratory challenges in the investigation of occupational asthma when laboratory challenges are negative in a hospital laboratory. The recommendation is to start the investigation in the hospital laboratory if an agent known to cause occupational asthma is present at the workplace. If the potential agent is unknown, or multiple agents are present at the workplace, testing can be initiated at the workplace.

\section{ACKNOWLEDGEMENTS}

The authors express their gratitude to K. Lieber for revising their work.

\section{REFERENCES}

1 Bernstein IL, Bernstein DI, Chan-Yeung M, Malo JL. Definition and classification of asthma in the workplace. In: Bernstein IL, Chan-Yeung M, Malo JL, Berstein DI, eds. Asthma in the Workplace. 3rd Edn. New York, Taylor and Francis, 2006; pp. 1-8.
2 Blanc PD, Toren K. How much asthma can be attributed to occupational factors? Am J Med 1999; 107: 580-587.

3 Chan-Yeung M, Malo JL. Occupational asthma. N Engl J Med 1995; 333: 107-112.

4 Vandenplas O, Toren K, Blanc P. Health and socioeconomic impact of work-related asthma. Eur Respir J 2003; 22: 689-697.

5 Bernstein DI, Campo P, Baur X. Clinical assessment and management of occupational asthma. In: Bernstein IL, Chan-Yeung M, Malo JL, Bernstein DI., eds. Asthma in the Workplace 3rd Edn. New York, Taylor and Francis, 2006; pp. 161-178.

6 Vandenplas O, Malo JL. Inhalation challenges with agents causing occupational asthma. Eur Respir J 1997; 10: 2612-2629.

7 Vandenplas O, Cartier A, Malo JL. Occupational challenge tests. In: Bernstein IL, Chan-Yeung M, Malo JL, Bernstein DI, eds. Asthma in the Workplace, 3rd Edn. New York, Taylor and Francis, 2006; pp. 227-252.

8 Pepys J, Hutchcroft BJ. Bronchial provocation tests in etiologic diagnosis and analysis of asthma. Am Rev Respir Dis 1975; 112: 829-859.

9 Malo JL, Cartier A, Lemière C, et al. Exaggerated bronchoconstriction due to inhalation challenges with occupational agents. Eur Respir J 2004; 23: 300-303.

10 Moscato G, Malo JL, Bernstein D. Diagnosing occupational asthma: how, how much, how far? Eur Respir J 2003; 21: 879-885.

11 American Thoracic Society. Standardization of spirometry, 1994 update. Am J Respir Crit Care Med 1995; 152: 1107-1136.

12 Cockcroft DW, Killian DN, Mellon JJA, Hargreave FE. Bronchial reactivity to inhaled histamine: a method and clinical survey. Clin Allergy 1977; 7: 235-243.

13 Dehaut P, Rachiele A, Martin RR, Malo JL. Histamine doseresponse curves in asthma: reproducibility and sensitivity of different indices to assess response. Thorax 1983; 38: 516-522.

14 Lemière C, Cartier A, Malo JL, Lehrer SB. Persistent specific bronchial reactivity to occupational agents in workers with normal nonspecific bronchial reactivity. Am J Respir Crit Care Med 2000; 162: 976-980.

15 Pisati G, Baruffini A, Bernabeo F, Cerri S, Mangili A. Rechallenging subjects with occupational asthma due to toluene diisocyanate (TDI), after long-term removal from exposure. Int Arch Occup Environ Health 2007; 80: 298-305.

16 Malo JL, Ghezzo H, L'Archevêque J, Lagier F, Perrin B, Cartier A. Is the clinical history a satisfactory means of diagnosing occupational asthma? Am Rev Respir Dis 1991; 143: 528-532.

17 Cartier A, L'Archevêque J, Malo JL. Exposure to a sensitizing occupational agent can cause a long-lasting increase in bronchial responsiveness to histamine in the absence of significant changes in airway caliber. J Allergy Clin Immunol 1986; 78: 1185-1189.

18 Sastre J, Fernandez-Nieto M, Novalbos A, De Las Heras M, Cuesta J, Quirce S. Need for monitoring nonspecific bronchial hyperresponsiveness before and after isocyanate inhalation challenge. Chest 2003; 123: 1276-1279.

19 Vandenplas O, Delwiche JP, Jamart J, Van de Weyer R. Increase in nonspecific bronchial hyperresponsiveness as an early marker of bronchial response to occupational agents during specific inhalation challenges. Thorax 1996; 51: 472-478. 
20 Girard F, Chaboillez S, Cartier A, et al. An effective strategy for diagnosing occupational asthma. Induced sputum. Am J Respir Crit Care Med 2004; 170: 845-850.

21 Lemière $C$, Romeo $\mathrm{P}$, Chaboillez $\mathrm{S}$, Tremblay C, Malo JL. Airway inflammation and functional changes after exposure to different concentrations of isocyanates. J Allergy Clin Immunol 2002; 110: 641-646.

22 Burge PS, Moscato G, Johnson A, Chan-Yeung M. Physiological assessment: serial measurements of lung function and bronchial responsiveness. In: Bernstein IL, ChanYeung M, Malo JL, Bernstein DI, eds. Asthma in the Workplace. 3rd Edn. New York, Taylor and Francis, 2006; pp. 199-206.

23 Malo JL, Cartier A, Ghezzo H, Chan-Yeung M. Compliance with peak expiratory flow readings affects the within- and between-reader reproducibility of interpretation of graphs in subjects investigated for occupational asthma. J Allergy Clin Immunol 1998; 98: 1132-1134. 